\title{
PENGARUH PENJUALAN ADAPTIF, KEMAMPUAN MENDENGAR DAN ORIENTASI PELANGGAN TERHADAP KINERJA TENAGA PENJUAL JASA HOTEL BINTANG 4 \& 5 DI YOGYAKARTA
}

\section{LEONITA AGUSTINA}

\author{
Fakultas Ekonomi \\ Universitas Sarjanawiyata Tamansiswa Yogyakarta \\ leonitaagustina@ymail.com
}

\begin{abstract}
The purpose of this exploratory was to examine the possible impact of the content adaptive selling, listening and customer orientation, based sales performance. Eighty eight sales people were surveyed by questionnaire. Result indicated that adaptive selling positively influence sales performance. Listening positively influence sales performance. Customer orientation positively influence sales performance. Listening is a stronger influence on sales performance. All result was using a hipotesis test.
\end{abstract}

Keywords : adaptive selling, listening, customer orientation.

Ketatnya persaingan antar hotel dalam era ekonomi global menuntut hotel untuk selalu menjadi yang terdepan dan terbaik dalam memberikan pelayanan yang memuaskan kepada konsumen. Persaingan yang terjadi merupakan suatu bagian yang tidak terpisahkan dari perhotelan, karena dengan adanya persaingan tersebut dapat menjadi salah satu pendorong dalam menyusun strategi pemasaran yang tepat, dapat memberikan keuntungan positif bagi perusahaan dalam meningkatkan volume penjualan dan pangsa pasar sehingga mampu memenangkan persaingan dipasar. Salah satu strategi yang dapat digunakan sebagai pendukung keberhasilan hotel yaitu sumber daya manusia yang berkualitas. Sumber daya manusia ini harus memiliki kemampuan penjualan adaptif, kemampuan mendengar dan orientasi pelanggan, strategi ini lah yang digunakan untuk meningkatkan kinerja tenaga penjual. Penjualan adaptif adalah penjualan dimana tenaga pemasar sedemikian fleksibel untuk pendekatan kepada konsumen, merasa percaya diri ketika harus merubah rencana, serta mencari cara presentasi yang sesuai untuk satu konsumen dengan konsumen yang lain. Tenaga pemasar sebagai pendengar bagi konsumen dengan menanyakan kesulitan yang dialami Kerangka Berpikir konsumen, dengan menanyakan permasalahan dengan lebih detail dan berusaha untuk melihat permasalahan dari segi pandang konsumen. Orientasi pelanggan adalah bagaimana kita memandang pemahaman kebutuhan dari sasaran konsumen dan menyesuaikan respon dari organisasi penjualan yang bertujuan untuk memuaskan mereka. Kinerja pemasaran merupakan pendapatan utama perusahaan, karena jika kinerja pemasaran produk maupun jasa tidak dikelola dengan baik maka secara langsung dapat merugikan perusahaan. Penulisan skripsi ini dimaksudkan untuk mengetahui pengaruh penjualan adaptif terhadap kinerja tenaga penjual jasa hotel bintang 4 \& 5 di Yogyakarta, untuk mengetahui pengaruh kemampuan mendengar terhadap kinerja tenaga penjual jasa hotel bintang $4 \& 5$ di Yogyakarta, untuk mengetahui pengaruh orientasi pelanggan terhadap kinerja tenaga penjual jasa hotel bintang 4 \& 5 di Yogyakarta, untuk mengetahui pengaruh penjualan adaptif, kemampuan mendengar dan orientasi pelanggan terhadap kinerja tenaga penjual jasa hotel bintang 4 \& 5 di Yogyakarta dan untuk mengetahui manakah variabel yang paling mempengaruhi kinerja tenaga penjual jasa hotel bintang 4 \& 5 di Yogyakarta. 


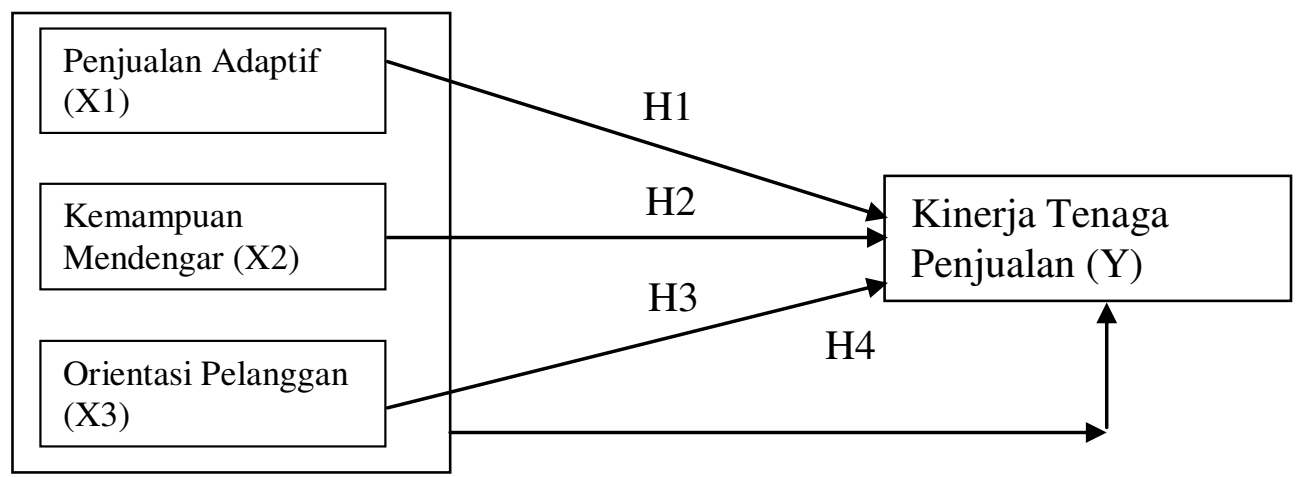

\section{Metode Penelitian}

Sifat penelitian yang digunakan adalah analisis deskriptif, analisis deskriptif adalah analisa data secara kualitatif dengan menggunakan table frekuensi dengan tujuan untuk memberikan gambaran (deskripsi) mengenai data-data penelitian yang terkumpul untuk diambil kesimpulan.

Jumlah sampel dalam penelitian ini adalah 88 sales hotel berbintang di Yogyakarta. Data yang diperlukan didasarkan pada sumbernya, yaitu data primer saja, yaitu data yang diperoleh secara langsung dengan obyek dan masalah yang diteliti. Data primer tersebut merupakan informasi yang diperoleh dari dengan mengunakan instrumen kuisioner.

Pengumpulan data pada penelitian kali ini menggunakan instrumen berupa kuisioner, yaitu suatu teknik pengumpulan data dan informasi dengan cara penyebaran daftar pertanyaan kepada sales Hotel di Yogyakarta.

Metode analisis data yang digunakan dalam penelitian ini adalah sebagai berikut:

a. Asumsi Klasik

\section{Uji Normalitas}

Uji normalitas adalah membandingkan antara data yang kita miliki dengan data berdistribusi normal yang memiliki mean dan standar deviasi yang sama dengan data yang kita miliki. Jika probabilitas $>0,05$, maka distribusi data normal. 2. Multikolinearitas

Multikolinearitas adalah untuk melihat ada atau tidaknya korelasi yang tinggi antara variabelvariabel bebas dalam suatu model regresi linear berganda. Bila nilai VIF lebih kecil dari 10 Hasil dan Pembahasan maka hal tersebut menunjukkan bahwa tidak terjadi multikolinearitas (Sugiyono, 2006:104).

\section{b. Uji Hipotesis}

1. Persamaan Linier Berganda

Analisis ini untuk mengetahui arah hubungan antara variabel independen dengan variabel dependen apakah masing-masing variabel independen berhubungan positif atau negatif dan untuk memprediksi nilai variabel dependen apabila nilai variabel independen mengalami kenaikan atau penurunan.

\section{Uji F}

Pengujian ini dilakukan untuk mengetahui koefisien regresi variabel bebas atau independen yaitu pengaruh secara simultan penjualan adaptif, kemampuan mendengar dan orientasi pelangganterhadap kinerja tenaga penjual. Uji $\mathrm{F}$ dilakukan dengan membandingkan nilai Fhitung dengan F-tabel pada taraf signifikan 0,05 .

\section{Koefisien Determinasi}

Koefisien determinasi ini mencari seberapa besar sumbangan (kontribusi) variabel.

\section{Uji t}

Untuk mengetahui tingkat signifikansi dari masing-masing koefisien regresi tersebut.

5. Uji Stepwise

Uji Stepwise ini digunakan untuk mengetahui variabel manakah diantara variabel penjualan adaptif, variabel kemampuan mendengar dan orientasi pelanggan yang paling mempengaruhi kinerja tenaga penjual jasa hotel bintang $4 \& 5$ di Yogyakarta. 


\section{JURNAL MANAJEMEN VOL. 6 NO. 1 JUNI 2016}

Karakteristik Responden :

\section{Jenis Kelamin}

Data karakteristik responden menurut jenis kelamin dapat dilihat sebagai berikut :

Jenis Kelamin Responden

\begin{tabular}{|l|c|c|}
\hline Jenis Kelamin & Jumlah & Persentase \\
\hline Laki-laki & 38 & $43 \%$ \\
\hline Perempuan & 50 & $57 \%$ \\
\hline \multicolumn{1}{|c|}{ Jumlah } & 88 & $100 \%$ \\
\hline
\end{tabular}

Sumber: Data Primer (2015)

\section{Usia Responden}

Pengelompokan berdasarkan usia dapat dilihat pada tabel berikut:

Jumlah Usia Responden

\begin{tabular}{|c|c|c|}
\hline Pendidikan & Jumlah & Persentase \\
\hline $20-25$ tahun & 18 & $20 \%$ \\
\hline $26-35$ tahun & 35 & $40 \%$ \\
\hline $36-45$ tahun & 24 & $27 \%$ \\
\hline$>45$ tahun & 11 & $13 \%$ \\
\hline Jumlah & 88 & $100 \%$ \\
\hline
\end{tabular}

Sumber: Data Primer Diolah, (2015)

\section{Deskriptiif Variabel Penelitian :}

\section{Variabel Penjualan Adaptif}

Variabel kelompok acuan mempunyai 6 item pertanyaan, sehingga diperoleh nilai skor total maksimal adalah 30 dan total skor minimal adalah 6. Sehingga diperoleh interval data dengan perhitungan sebagai berikut (Sri Mulyono, 1991:9):

Interval $=($ Skor tertinggi - Skor terendah) / Jumlah Katagori

$$
\begin{aligned}
& =(30-6) / 5 \\
& =4,8
\end{aligned}
$$

Data Variabel Penjualan Adaptif

\begin{tabular}{|c|c|c|c|}
\hline Kelas & Kategori & Jumlah & Prosentase \\
\hline $6-10,8$ & Sangat Tidak Setuju & 0 & $0 \%$ \\
\hline $10,9-15,6$ & Tidak Setuju & 0 & $0 \%$ \\
\hline $15,7-20,4$ & Netral & 29 & $32,9 \%$ \\
\hline $20,5-25,2$ & Setuju & 50 & $56,9 \%$ \\
\hline $25,3-30$ & Sangat Setuju & 9 & $10,1 \%$ \\
\hline \multicolumn{2}{|l}{ Jumlah } & 88 & $100 \%$ \\
\hline
\end{tabular}

Sumber: Data Primer Diolah, (2015)

\begin{tabular}{|c|c|c|c|c|c|c|c|c|c|c|c|}
\hline \multirow{3}{*}{ No. } & \multirow{3}{*}{ Pernyataan } & \multicolumn{10}{|c|}{ Pilihan Jawaban } \\
\hline & & \multicolumn{2}{|c|}{ SS } & \multicolumn{2}{|c|}{$\mathrm{S}$} & \multicolumn{2}{|c|}{$\mathrm{N}$} & \multicolumn{2}{|c|}{ TS } & \multicolumn{2}{|c|}{ STS } \\
\hline & & $\mathrm{F}$ & $\%$ & $\mathrm{~F}$ & $\%$ & $\mathrm{~F}$ & $\%$ & $\mathrm{~F}$ & $\%$ & $\mathrm{~F}$ & $\%$ \\
\hline 1. & $\begin{array}{l}\text { Ketika saya merasa pendekatan penjualan saya } \\
\text { tidak berjalan, saya mengganti dengan cara } \\
\text { pendekatan lain }\end{array}$ & 8 & 9,1 & 51 & 58 & 27 & 30,7 & 2 & 2,3 & 0 & 0 \\
\hline 2. & Saya merasa sukar mengadaptasikan cara & 16 & 18,2 & 39 & 44,3 & 22 & 25 & 11 & 12,5 & 0 & 0 \\
\hline
\end{tabular}

Gambaran Rinci Jawaban Responden Tentang Variabel Penjualan Adaptif 
JURNAL MANAJEMEN VOL. 6 NO. 1 JUNI 2016

\begin{tabular}{|c|l|l|l|l|l|l|l|l|l|l|l|}
\hline & presentasi saya ke pelanggan tertentu & & & & & & & & & \\
\hline 3. & $\begin{array}{l}\text { Saya memvariasi gaya penjualan menyesuaikan } \\
\text { situasi yang ada }\end{array}$ & 11 & 12,5 & 41 & 46,6 & 30 & 34,1 & 6 & 6,8 & 0 & 0 \\
\hline 4. & $\begin{array}{l}\text { Saya merasa percaya diri ketika saya bisa } \\
\text { dengan efektif mengganti rencana presentasi } \\
\text { saat dibutuhkan }\end{array}$ & 11 & 12,5 & 33 & 37,5 & 39 & 44,3 & 5 & 5,7 & 0 & 0 \\
\hline 5. & $\begin{array}{l}\text { Pada dasarkan, saya menggunakan strategi } \\
\text { berbeda hampir pada sebagian besar pelanggan }\end{array}$ & 11 & 12,5 & 39 & 44,3 & 35 & 39,8 & 3 & 3,4 & 0 & 0 \\
\hline 6. & $\begin{array}{l}\text { Saya mencoba untuk mengerti bagaimana } \\
\text { seorang pelanggan berbeda dengan pelanggan } \\
\text { yang lain }\end{array}$ & 10 & 11,4 & 54 & 61,4 & 23 & 26,1 & 1 & 1,1 & 0 & 0 \\
\hline
\end{tabular}

\section{Variabel Kemampuan Mendengar}

Variabel keluarga mempunyai7 item pertanyaan, sehingga diperoleh nilai skor total maksimal adalah 35 dan total skor minimal adalah 7 Sehingga diperoleh interval data dengan perhitungan sebagai berikut (Sri Mulyono, 1991:9):

Interval $=($ Skor tertinggi - Skor

terendah) / Jumlah Katagori

$=(35-7) / 5$

$=5,6$

Data Variabel Kemampuan Mendengar

\begin{tabular}{|c|c|c|c|}
\hline Kelas & Kategori & Jumlah & Prosentase \\
\hline $7-12,6$ & Sangat Tidak Setuju & 0 & $0 \%$ \\
\hline $12,7-18,2$ & Tidak Setuju & 0 & $0 \%$ \\
\hline $18,3-23,8$ & Netral & 9 & $10,2 \%$ \\
\hline $23,9-29,4$ & Setuju & 74 & $84 \%$ \\
\hline $29,5-35$ & Sangat Setuju & 5 & $5,7 \%$ \\
\hline \multicolumn{2}{|c|}{ Jumlah } & 88 & $100 \%$ \\
\hline
\end{tabular}

Sumber: Data Primer Diolah, (2015)

Gambaran Rinci Jawaban Responden Tentang Variabel Kemampuan Mendengar

\begin{tabular}{|c|c|c|c|c|c|c|c|c|c|c|c|}
\hline \multirow{3}{*}{ No. } & \multirow{3}{*}{ Pernyataan } & \multicolumn{10}{|c|}{ Pilihan Jawaban } \\
\hline & & \multicolumn{2}{|c|}{ SS } & \multicolumn{2}{|c|}{$S$} & \multicolumn{2}{|c|}{$\mathrm{N}$} & \multicolumn{2}{|c|}{ TS } & \multicolumn{2}{|c|}{ STS } \\
\hline & & $\mathrm{F}$ & $\%$ & $\mathrm{~F}$ & $\%$ & $\mathrm{~F}$ & $\%$ & $\mathrm{~F}$ & $\%$ & $\mathrm{~F}$ & $\%$ \\
\hline 1. & $\begin{array}{l}\text { Saya berencana pada kesan pertama } \\
\text { memperlihatkan bahwa saya peduli dengan } \\
\text { apa yang pembeli katakan }\end{array}$ & 7 & 8 & 36 & 40,9 & 44 & 50 & 1 & 1,1 & 0 & 0 \\
\hline 2. & $\begin{array}{l}\text { Saya tidak mengambil keputusan sendiri } \\
\text { dengan pelanggan saya }\end{array}$ & 5 & 5,7 & 55 & 62,5 & 25 & 28,4 & 3 & 3,4 & 0 & 0 \\
\hline 3. & $\begin{array}{l}\text { Saya bertanya banyak tentang masalah yang } \\
\text { dihadapi pelanggan saya }\end{array}$ & 4 & 4,5 & 57 & 64,8 & 24 & 27,3 & 3 & 3,4 & 0 & 0 \\
\hline 4. & $\begin{array}{l}\text { Saya mempertahankan kontak mata dengan } \\
\text { pelanggan }\end{array}$ & 1 & 1,1 & 54 & 61,4 & 30 & 34,1 & 3 & 3,4 & 0 & 0 \\
\hline 5. & $\begin{array}{l}\text { Saya menunggu pelanggan selesai bicara } \\
\text { sebelum mengevaluasi apa yang terjadi sesuai } \\
\text { dengan yang dikatakan }\end{array}$ & 22 & 25 & 50 & 56,8 & 16 & 18,2 & 0 & 0 & 0 & 0 \\
\hline
\end{tabular}




\section{JURNAL MANAJEMEN VOL. 6 NO. 1 JUNI 2016}

\begin{tabular}{|l|l|r|r|r|r|r|r|r|r|r|r|}
\hline 6. & $\begin{array}{l}\text { Saya mengemukakan kembali apa yang } \\
\text { pelanggan sampaikan/tanyakan }\end{array}$ & 1 & 1,1 & 38 & 43,2 & 23 & 26,1 & 3 & 3,4 & 0 & 0 \\
\hline 7. & $\begin{array}{l}\text { Saya berusaha mengerti permasalahan dari } \\
\text { pandangan pelanggan }\end{array}$ & 13 & 14,8 & 42 & 47,7 & 24 & 27,3 & 9 & 10,2 & 0 & 0 \\
\hline
\end{tabular}

\section{Variabel Orientasi Pelanggan}

Variabel peran dan status mempunyai5 item pertanyaan, sehingga diperoleh nilai skor total maksimal adalah 25 dan total skor minimal adalah

5. Sehingga diperoleh interval data dengan perhitungan sebagai berikut (Sri Mulyono, 1991:9):

Interval $=($ Skor tertinggi - Skor terendah) / Jumlah Katagori

$$
\begin{aligned}
& =(25-5) / 5 \\
& =4
\end{aligned}
$$

Data Variabel Orientasi Pelanggan

\begin{tabular}{|c|c|c|c|}
\hline Kelas & Kategori & Jumlah & Prosentase \\
\hline $5-9$ & Sangat Tidak Setuju & 0 & $0 \%$ \\
\hline $10-13$ & Tidak Setuju & 2 & $2,3 \%$ \\
\hline $14-17$ & Netral & 44 & $49,9 \%$ \\
\hline $18-21$ & Setuju & 33 & $51,1 \%$ \\
\hline $22-25$ & Sangat Setuju & 9 & $10,2 \%$ \\
\hline \multicolumn{2}{|c|}{ Jumlah } & 88 & $100 \%$ \\
\hline
\end{tabular}

Sumber: Data Primer Diolah, (2015)

\begin{tabular}{|c|c|c|c|c|c|c|c|c|c|c|c|}
\hline \multirow{3}{*}{ No. } & \multirow{3}{*}{ Pernyataan } & \multicolumn{10}{|c|}{ Pilihan Jawaban } \\
\hline & & \multicolumn{2}{|c|}{ SS } & \multicolumn{2}{|c|}{$S$} & \multicolumn{2}{|c|}{$\mathrm{N}$} & \multicolumn{2}{|c|}{$\mathrm{TS}$} & \multicolumn{2}{|c|}{ STS } \\
\hline & & $\mathrm{F}$ & $\%$ & $\mathrm{~F}$ & $\%$ & $\mathrm{~F}$ & $\%$ & $\mathrm{~F}$ & $\%$ & $\mathrm{~F}$ & $\%$ \\
\hline 1. & $\begin{array}{l}\text { Saya mencoba mencari tahu } \\
\text { kebutuhan pelanggan }\end{array}$ & 11 & 12,5 & 36 & 40,9 & 33 & 37,5 & 8 & 9,1 & 0 & 0 \\
\hline 2. & $\begin{array}{l}\text { Saya mengambil pendekatan } \\
\text { pemecahan masalah dalam } \\
\text { menjual produk/jasa kepada } \\
\text { pelanggan }\end{array}$ & 11 & 12,5 & 36 & 40,9 & 33 & 37,5 & 8 & 9,1 & 0 & 0 \\
\hline 3. & $\begin{array}{l}\text { Saya mencoba untuk mengetahui } \\
\text { jenis produk atau jasa yang akan } \\
\text { sangat membantu untuk pelanggan } \\
\text { saya }\end{array}$ & 10 & 11,4 & 52 & 59,1 & 23 & 26,1 & 3 & 3,4 & 0 & 0 \\
\hline 4. & $\begin{array}{l}\text { Menyatakan keuntungan- } \\
\text { keuntungan pada penawaran dan } \\
\text { melihat apakah pelanggan tertarik } \\
\text { dengan hal tersebut }\end{array}$ & 11 & 12,5 & 32 & 36,4 & 30 & 34,1 & 15 & 17 & 0 & 0 \\
\hline 5. & $\begin{array}{l}\text { Mengakui keberatan terhadap } \\
\text { pelanggan, tetapi menunjukan } \\
\text { keuntungan yang mengkompensasi } \\
\text { keberatan }\end{array}$ & 37 & 42 & 28 & 31,8 & 14 & 15,9 & 0 & 0 & 0 & 0 \\
\hline
\end{tabular}

Gambaran Rinci Jawaban Responden Tentang Variabel Orientasi Pelanggan 


\section{Kinerja Tenaga Penjual}

Variabel keputusan pembelian mempunyai5 item pertanyaan, sehingga diperoleh nilai skor total maksimal adalah 25 dan total skor minimal adalah 5. Sehingga diperoleh interval data dengan perhitungan sebagai berikut (Sri Mulyono, 1991:9):

Interval $=($ Skor tertinggi - Skor terendah) / Jumlah Katagori

$$
\begin{aligned}
& =(25-5) / 5 \\
& =4
\end{aligned}
$$

\begin{tabular}{|c|c|c|c|}
\hline Kelas & Kategori & Jumlah & Prosentase \\
\hline $5-9$ & Sangat Tidak Setuju & 0 & $0 \%$ \\
\hline $10-13$ & Tidak Setuju & 9 & $10,2 \%$ \\
\hline $14-17$ & Netral & 21 & $23,8 \%$ \\
\hline $18-21$ & Setuju & 51 & $58 \%$ \\
\hline $22-25$ & Sangat Setuju & 7 & $8 \%$ \\
\hline \multicolumn{2}{|r|}{ Jumlah } & 88 & $100 \%$ \\
\hline
\end{tabular}

Data Variabel Kinerja Tenaga Penjual

Sumber: Data Primer Diolah, (2015)

Tabel 4.10

Gambaran Rinci Jawaban Responden

\begin{tabular}{|c|c|c|c|c|c|c|c|c|c|c|c|}
\hline \multirow{3}{*}{ No. } & \multirow{3}{*}{ Pernyataan } & \multicolumn{10}{|c|}{ Pilihan Jawaban } \\
\hline & & \multicolumn{2}{|c|}{ SS } & \multicolumn{2}{|c|}{$\mathrm{S}$} & \multicolumn{2}{|c|}{$\mathrm{N}$} & \multicolumn{2}{|c|}{$\mathrm{TS}$} & \multicolumn{2}{|c|}{ STS } \\
\hline & & $\mathrm{F}$ & $\%$ & $\mathrm{~F}$ & $\%$ & $\mathrm{~F}$ & $\%$ & $\mathrm{~F}$ & $\%$ & $\mathrm{~F}$ & $\%$ \\
\hline 1. & $\begin{array}{l}\text { Saya berpengaruh terhadap pilihan } \\
\text { pelanggan }\end{array}$ & 13 & 14,8 & 33 & 37,5 & 25 & 28,4 & 15 & 17 & 2 & 2,3 \\
\hline 2. & $\begin{array}{l}\text { Saran saya berpengaruh terhadap keputusan } \\
\text { pelanggan }\end{array}$ & 16 & 18,2 & 39 & 44,3 & 22 & 25 & 11 & 12,5 & 0 & 0 \\
\hline 3. & $\begin{array}{l}\text { Saya meyakinkan pelanggan bahwa saya } \\
\text { tahu kebutuhan pelanggan }\end{array}$ & 1 & 1,1 & 29 & 33 & 23 & 26,1 & 30 & 34,1 & 5 & 5,7 \\
\hline 4. & $\begin{array}{l}\text { Saya menggunakan database untuk } \\
\text { mendapatkan pelanggan baru }\end{array}$ & 13 & 14,8 & 39 & 44,3 & 24 & 27,3 & 11 & 12,5 & 1 & 1,1 \\
\hline 5. & $\begin{array}{l}\text { Saya menggunakan alat bantu audiovisual } \\
\text { yang efektif untuk meningkatkan kinerja }\end{array}$ & 39 & 44,3 & 48 & 54,5 & 1 & 1,1 & 0 & 0 & 0 & 0 \\
\hline
\end{tabular}

Tentang Variabel Kinerja Tenaga Penjual

Uji Validitas dan Reliabilitas :

1. Pengujian Validitas dan Reliabilitas Variabel Penjualan Adaptif

Uji Validitas dan ReliabilitasVariabel Penjualan Adaptif

\begin{tabular}{|c|c|c|c|c|}
\hline Butir & $\mathbf{r}$ & $\mathbf{r}$ table & Sig & Keterangan \\
\hline PA1 & 0,652 & 0,2096 & 0,000 & Valid \\
\hline PA2 & 0,381 & 0,2096 & 0,000 & Valid \\
\hline PA3 & 0,682 & 0,2096 & 0,000 & Valid \\
\hline PA4 & 0,640 & 0,2096 & 0,000 & Valid \\
\hline PA5 & 0,672 & 0,2096 & 0,000 & Valid \\
\hline PA6 & 0,531 & 0,2096 & 0,000 & Valid \\
\hline
\end{tabular}




\section{JURNAL MANAJEMEN VOL. 6 NO. 1 JUNI 2016}

\begin{tabular}{|c|c|}
\hline Alpha & Keterangan \\
\hline $\mathbf{0 , 7 3 1}$ & Reliabel \\
\hline
\end{tabular}

2. Pengujian Validitas dan Reliabilitas Kemampuan Mendengar

Uji Validitas dan Reliabilitas Kemampuan Mendengar

\begin{tabular}{|c|c|c|c|c|}
\hline Butir & r & r table & Sig & Keterangan \\
\hline KM1 & 0,543 & 0,2096 & 0,000 & Valid \\
\hline KM2 & 0,534 & 0,2096 & 0,000 & Valid \\
\hline KM3 & 0,558 & 0,2096 & 0,000 & Valid \\
\hline KM4 & 0,571 & 0,2096 & 0,000 & Valid \\
\hline KM5 & 0,214 & 0,2096 & 0,000 & Valid \\
\hline KM6 & 0,488 & 0,2096 & 0,000 & Valid \\
\hline KM7 & 0,523 & 0,2096 & 0,000 & Valid \\
\hline \multicolumn{2}{|c|}{ Alpha } & \multicolumn{3}{|c|}{ Keterangan } \\
\hline \multicolumn{2}{|c|}{ 0,681 } & \multicolumn{3}{c}{ Reliabel } \\
\hline
\end{tabular}

3. Pengujian Validitas dan Reliabilitas Orientasi Pelanggan

Uji Validitas dan ReliabilitasVariabel Orientasi Pelanggan

\begin{tabular}{|c|c|c|c|c|}
\hline Butir & r & r table & Sig & Keterangan \\
\hline OP1 & 0,630 & 0,2096 & 0,000 & Valid \\
\hline OP2 & 0,650 & 0,2096 & 0,000 & Valid \\
\hline OP3 & 0,665 & 0,2096 & 0,000 & Valid \\
\hline OP4 & 0,682 & 0,2096 & 0,000 & Valid \\
\hline OP5 & 0,551 & 0,2096 & 0,000 & Valid \\
\hline \multicolumn{2}{|c|}{ Alpha } & \multicolumn{3}{|c|}{ Keterangan } \\
\hline \multicolumn{2}{|c|}{$\mathbf{0 , 7 5 0}$} & \multicolumn{3}{c|}{ Reliabel } \\
\hline
\end{tabular}

4. Pengujian Validitas dan Reliabilitas Variabel Kinerja Tenaga Penjualan Uji Validitas dan Reliabilitas Variabel Kinerja Tenaga Penjualan

\begin{tabular}{|c|c|c|c|c|}
\hline Butir & r & r table & Sig & Keterangan \\
\hline KTP1 & 0,786 & 0,2096 & 0,000 & Valid \\
\hline KTP2 & 0,879 & 0,2096 & 0,000 & Valid \\
\hline KTP3 & 0,485 & 0,2096 & 0,000 & Valid \\
\hline KTP4 & 0,697 & 0,2096 & 0,000 & Valid \\
\hline KTP5 & 0,320 & 0,2096 & 0,000 & Valid \\
\hline \multicolumn{2}{|c|}{ Alpha } & \multicolumn{3}{c|}{ Keterangan } \\
\hline \multicolumn{2}{|c|}{ 0,758 } & \multicolumn{3}{c|}{ Reliabel } \\
\hline
\end{tabular}




\section{Analisis Data :}

\section{Uji Normalitas}

\section{Hasil Uji Normalitas}

One-Sample Kolmogorov-Smirnov Test

\begin{tabular}{|c|c|c|}
\hline & & $\begin{array}{c}\text { Unstandardized } \\
\text { Residual }\end{array}$ \\
\hline \multicolumn{2}{|l|}{$\mathrm{N}$} & 88 \\
\hline Normal & Mean & $0 \mathrm{E}-7$ \\
\hline Parameters ${ }^{\mathrm{a}, \mathrm{b}}$ & $\begin{array}{l}\text { Std. } \\
\text { Deviation }\end{array}$ & 2.50920157 \\
\hline Extreme & Absolute & .111 \\
\hline Differences & Positive & $\begin{array}{r}.068 \\
-111\end{array}$ \\
\hline \multicolumn{2}{|c|}{ Kolmogorov-Smirnov Z } & 1.042 \\
\hline \multicolumn{2}{|c|}{ Asymp. Sig. (2-tailed) } & .228 \\
\hline
\end{tabular}

a. Test distribution is Normal.

b. Calculated from data.

Hasil menunjukkan bahwa nilai Kolmogrov-Smirnov Zsebesar 1,042 dan nilaiAsymp. Sig. (2-tailed) sebesar 0,228

yang diperoleh model regresi lebih dari $\alpha \quad(0,05) \quad(0,228>0,05), \quad$ berarti berdistribusi normal.

\section{Hasil Uji Multikolinieritas}

\begin{tabular}{|l|r|r|}
\hline \multirow{2}{*}{ Model } & \multicolumn{2}{|c|}{ Collinearity Statistics } \\
\cline { 2 - 3 } & Tolerance & VIF \\
\hline 1 (Constant) & & \\
Penjualan Adaptif & 1.983 & 1.983 \\
Kemampuan Mendengar & 1.219 & 1.219 \\
Orientasi Pelanggan & 1.833 & 1.833 \\
\hline
\end{tabular}

Sumber: Data diolah, 2015

Dari hasil olah data tersebut, dapat dilihat nilai terjadi multikolinieritas sehingga model VIF semua variabel memiliki nilai VIF $<10$, regresinya dapat digunakan. sehingga model regresi tersebut di atas tidak

\section{Uji Heterokedastisitas}

\section{Nilai Uji Heteroskedastisitas}

\begin{tabular}{|c|c|c|c|c|}
\hline Variabel bebas & Sig & $\alpha$ & Keterangan & Kesimpulan \\
\hline Penjualan Adaptif & 0,698 & 0,05 & Tidak Signifikan & $\begin{array}{c}\text { Tidak Terjadi } \\
\text { Heteroskedastisitas }\end{array}$ \\
\hline Kemampuan Mendengar & 0,986 & 0,05 & Tidak Signifikan & $\begin{array}{c}\text { Tidak Terjadi } \\
\text { Heteroskedastisitas }\end{array}$ \\
\hline Orientasi Konsumen & 0,751 & 0,05 & Tidak Signifikan & $\begin{array}{c}\text { Tidak Terjadi } \\
\text { Heteroskedastisitas }\end{array}$ \\
\hline
\end{tabular}

Sumber: Data diolah, 2015

Dari tabel diatas diperoleh bahwa seluruh variabel bebas mempunyai nilai probabilitas yang lebih besar dari taraf signifikan 0,05 , sehingga dapat disimpulkan bahwa dalam model regresi tersebut tidak terjadi Heteroskedastisitas 


\section{Analisis Regresi Berganda}

\section{Hasil Pengujian Regresi Berganda}

\begin{tabular}{|l|r|}
\hline Model & \multicolumn{2}{|c|}{ Standardized Coefficients } \\
\cline { 2 - 2 } & \multicolumn{2}{|c|}{ Beta } \\
\hline 1 (Constant) & .365 \\
Penjualan Adaptif & .363 \\
Kemampuan Mendengar & -.308 \\
\hline
\end{tabular}

Sumber: Data diolah, 2015

Berdasarkan tabel diatas, maka dapat diperoleh persamaan regresi sebagai berikut:

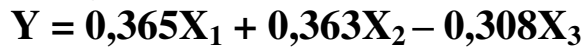

Koefisien beta penjualan adaptif bernilai positif, hal ini menunjukkan bahwa setiap kenaikan penjualan adaptif akan diikuti kenaikkan kinerja tenaga penjual. Koefisien beta kemampuan mendengar bernilai positif, hal ini menunjukkan bahwa setiap kenaikan kemampuan mendengar akan diikuti kenaikan kinerja tenaga penjual. Koefisien beta orientasi pelanggan bernilai negatif, hal ini menunjukkan bahwa setiap kenaikan orientasi pelangganakan tidak akan diikuti kenaikkan kinerja tenaga penjual.

\section{Uji t}

\begin{tabular}{|l|c|c|}
\multicolumn{3}{c|}{ Hasil Uji t } \\
\hline Model & & \\
& $\mathrm{t}$ & Sig. \\
\hline 1 (Constant) & 1.303 & .196 \\
Penjualan Adaptif & 2.736 & .008 \\
Kemampuan Mendengar & 3.470 & .001 \\
Orientasi Pelanggan & -2.403 & .018 \\
\hline
\end{tabular}

Sumber: Data diolah, 2015

Dari hasil olah data di atas diketahui t-hitung masing - masing variabel adalah :

1) Variabel penjualan adaptif acuan thitung lebih besar dari t-tabel $(2,736>1,98861)$ dengan probabilitas $(0,008)$ lebih kecildari taraf signifikan 0,05 , dengan demikian Ho ditolak dan $\mathrm{Ha}$ diterima, artinya variabel penjualan adaptifmempunyai pengaruh positif dansignifikan terhadap keputusan pembelian.

2) Variabel kemampuan mendengart thitung lebih besar dari t-tabel $(3,470>1,98861)$ dengan probabilitas $(0,001)$ lebih kecil dari taraf signifikan 0,05, dengan demikian Ho ditolak dan $\mathrm{Ha}$ diterima, artinya variabel kemampuan mendengarmempunyai pengaruh positif dan signifikan terhadap kinerja tenaga penjual.

3) Variabel orientasi pelanggan thitung lebih kecil dari t-tabel ($2,403<1,98861)$ dengan probabilitas $(0,018)$ lebih kecil dari taraf signifikan 0,05, dengan demikian Ho diterima dan $\mathrm{Ha}$ ditolak, artinya variabel orientasi pelanggan mempunyai pengaruh negatif dan tidak signifikan terhadap kinerja tenaga penjual. 


\section{Uji F}

Hasil Nilai Uji-F
\begin{tabular}{|l|c|c|}
\hline Model & F & Sig. \\
\hline $\begin{array}{l}\text { Regression } \\
\text { Residual }\end{array}$ & 9.148 & $.000^{\circ}$ \\
Total & & \\
\hline
\end{tabular}

Sumber: Data diolah, 2015

Dari hasil pengolahan data di atas diketahui bahwa nilai F-hitung adalah 9,148. Dengan nilai signifikan sebesar 0,000 , dan nilai F-tabel adalah 2,71. Dengan demikian dapat disimpulkan bahwa F-hitung $>$ F-tabel dengan tingkat signifikan $\quad 0,000<0,05 \quad(\mathrm{p}<0,05)$, maka Ho ditolak dan $\mathrm{Ha}$ diterima berarti variabel-variabel penjualan adaptif, kemampuan mendengar dan orientasi penjual secara simultan terhadap kinerja tenaga penjual.

\section{Koefesien Determinasi}

\section{Hasil Analisis Uji Koefisien Determinasi $\left(\mathbf{R}^{2}\right)$}

\begin{tabular}{|c|c|r|r|r|}
\hline Model & $\mathrm{R}$ & $\mathrm{R}$ Square & \multicolumn{1}{c|}{ Adjusted R Square } & Std. Error of the Estimate \\
\hline-1 & $.496^{\mathrm{a}}$ & .246 & .219 & 2.554 \\
\hline
\end{tabular}

a. Predictors: (Constant), Penjualan Adaptif, Kemampuan Mendengar, Orientasi Pelanggan Sumber: Data diolah, 2015

Dari perhitungan di atas diperoleh nilai Adjusted $\mathrm{R}^{2}=0,219$ atau $21,9 \%$, hal ini menunjukkan bahwa variasi kinerja tenaga penjual (Y) yang dapat dijelaskan variabel penjualan adaptif, kemampuan mendengar dan orientasi pelanggan sebesar $21,9 \%$. Sedangkan sisanya sebesar $78,1 \%$ dipengaruhi faktor lain.

\section{Uji Dominasi}

\section{Uji Stepwise}

Variables Entered/Removed ${ }^{\mathrm{a}}$

\begin{tabular}{|l|l|l|l|}
\hline Model & \multicolumn{1}{|l|}{$\begin{array}{c}\text { Variables } \\
\text { Entered }\end{array}$} & $\begin{array}{c}\text { Variables } \\
\text { Removed }\end{array}$ & \multicolumn{1}{c|}{ Method } \\
\hline 1 & KMTotal & & $\begin{array}{l}\text { Stepwise (Criteria: Probability-of-F-to-enter <= .050, Probability-of-F-to- } \\
\text { remove }>=.100) .\end{array}$ \\
\hline
\end{tabular}

a. Dependent Variable: KTPTotal

Berdasarkan hasil uji stepwise dapat dilaketahui bahwa faktor yang paling dominan mempengaruhi kinerja tenaga penjual adalah kemampuan mendengar. Sedangkan kedua factor lainnya tidak dimunculkan.

\section{Kesimpulan}

Berdasarkan hasil penelitian dan pembahasan pengaruh penjualan adaptif, kemampuan mendengar dan orientasi pelanggan terhadap kinerja tenaga penjual jasa hotel bintang $4 \& 5$ di Yogyakarta, maka dapat diambil beberapa kesimpulan sebagai berikut :

1. Hasil penelitian diperoleh persamaan regresi sebagai berikut: $Y=\mathbf{0 , 3 6 5} \mathbf{X}_{\mathbf{1}}+$ $0,363 X_{2}-0,308 X_{3}$

2. Penjualan adaptif berpengaruh positif dan signifikan terhadap keputusan pembelian. Adanya pengaruh ini menunjukkan semakin baik kemampuan tenaga penjual untuk beradaptasi, maka akan meningkatkan kinerja tenaga penjual jasa hotel bintang 4 \& 5 di 
Yogyakarta, hal ini ditunjukkan dengan nilai signifikan $<0,05$.

3. Kemampuan mendengar berpengaruh positif dan signifikan terhadap kinerja tenaga penjual jasa hotel bintang $4 \& 5$ di Yogyakarta. Adanya pengaruh ini menunjukkan semakin baik kemampuan mendengar tenaga penjual, maka akan meningkatkan kinerja tenaga penjual hotel bintang 4 \& 5 di Yogyakarta,hal ini ditunjukkan dengan nilai signifikan < 0,05

4. Orientasi Pelanggan berpengaruh positif dan signifikan terhadap keputusan pembelian. Adanya pengaruh ini menunjukkan semakin baik kemampuan tenaga penjual melihat sesuatu dari sudut pandang pelanggan, maka akan meningkatkan kinerja tenaga penjual jasa hotel bintang $4 \& 5$ di Yogyakarta, hal ini ditunjukkan dengan nilai signifikan $<0,05$.

5. Variabel-variabel penjualan adaptif, kemampuan mendengar dan orientasi

\section{Referensi}

Pelham, Alfred M. and Kravitz, Pamela, December 2008, “An Exploratory Study of the Influence of Sales Training Content and Salesperson Evaluation on Salesperson Adaptive Selling, Customer Orientationm, Listening, and Consulting Behaviors". Journal of Strategic Marketing. Volume 16, No. 5, http://www.informaworld.com, 25 October 2014

Rapp, Adam et al, 2008, "The Sales Force Technology-Performance Chain: The Role of Adaptive Selling and Effort". Journal of Personal Selling \& Sales Management. Volume 28, No. 4.

Kidwell, Blair et al, 2007, "Perceiving Emotion in the Buyer-Seller Interchange: the Moderated Impact on Performance". Journal of Personal Selling \& Sales Management. Volume 27, No. 2. pelanggan berpengaruh secara simultan terhadap kinerja tenaga penjual.

6. Penjualan adaptif, kemampuan mendengar dan orientasi pelanggan dapat mempengaruhi kinerja tenaga penjualan sebesar $21,9 \%$.

7. Faktor yang paling dominan mempengaruhi kinerja tenaga penjual adalah kemampuan mendengar.

\section{Saran}

Penelitian ini menunjukkan bahwa penjualan adaptif, kemampuan mendengar dan orientasi pelanggan berpengaruh signifikan terhadap kinerja tenaga penjual, disarankan kepada tenaga penjual jasa hotel bintang 4 \& 5 di Yogyakarta dapat terus meningkatkan kemampuannya dalam menjual seiring dengan bertumbuhnya bisnis hotel di Yogyakarta. Semakin banyaknya tenaga penjual, akan semakin dibutuhkan kemampuan menjual yang lebih baik agar tetap unggul dalam persaingan.

Jaramillo, Fernando et al, 2007, "Getting the Job Done: The moderating Role of Initiative on the Relationship Between Intrinsic Motivation and Adaptive Selling". Journal of Personal Selling \& Sales Management. Volume 27, No. 1.

Ranupandojo, Heidjrachman (1982). Pengantar Ekonomi Perusahaan. Yogyakarta: Penerbit BPFE.

Sugeng, 2011, definisi pemasaran. Diambil dari : http://skripsimanajemen.blogspot.com/2011/02/penge rtian-definisi-pemasaran.html 9 April 2015)

Hudri, Said (2013). Aplikasi Uji T. From http://expresisastra blogspot.com /2013/10/aplikasi-uji-t.html (15 Maret 2015)

Junaidi, 2012, t table. Diambil dari : http://www.unja.ac.id/fe/images/karyailmiah/tabel-t.pdf (29 Maret 2015) 
Samsuri, 2012, Antiseden Kinerja Tenaga Penjual dan Kinerja Pemasaran Asuransi Jiwa Bersama Bumi Putera 1912 Cabang Kabupaten Sleman Daerah Istimewa Yogyakarta. Diambil dari : http://thesis.umy.ac.id/datapublik/t18343.p df (23 April 2015)

Mulasih, Retno, 2012, Studi Tentang Kinerja Tenaga Penjualan. Diambil dari : http://stiepena.ac.id/wpcontent/uploads/2012/11/pena-fokus-vol-6no-1-19-39.pdf (23 April 2015)

Click, 2013, Tabel Statistik. Diambil dari : http://clickyhun.blogspot.com/2013/08/tabe 1-statistik-product-momen.html (24 April 2015)

Junaidi, 2010, Titik Persentase Distribusi t.

Diambil dari :

http://junaidichaniago.wordpress.com (24 April 2015) 